Research Article

\title{
Research on the Influence of Moisture Condition on the Mechanical Properties and Microstructure of Sandstone
}

\author{
Zuosen. Luo $\mathbb{D}^{1,2}$ Zuoxiang. Zhu, ${ }^{2}$ Hao Bai, ${ }^{2}$ Daxiang Liu, ${ }^{1}$ and Qiancheng. Sun $\mathbb{D}^{2}$ \\ ${ }^{1}$ Engineering Research Center of Eco-environment in Three Gorges Reservoir Region, Ministry of Education, \\ China Three Gorges University, Yichang 443002, China \\ ${ }^{2}$ Key Laboratory of Geological Hazards on Three Gorges Reservoir Area of Ministry of Education, China Three Gorges University, \\ Yichang, Hubei 443002, China \\ Correspondence should be addressed to Qiancheng. Sun; qc_sun@ctgu.edu.cn
}

Received 10 June 2021; Accepted 15 July 2021; Published 27 July 2021

Academic Editor: Zhigang Tao

Copyright (C) 2021 Zuosen. Luo et al. This is an open access article distributed under the Creative Commons Attribution License, which permits unrestricted use, distribution, and reproduction in any medium, provided the original work is properly cited.

\begin{abstract}
The sandstone from the dry to saturated state shows obvious deterioration characteristics. Taking the sandstone of a slope in the Three Gorges Reservoir area as the research object, uniaxial/triaxial compression of sandstone samples with different waterbearing states (dry, natural, and saturated) is carried out to study the changes in macromechanical properties of sandstone under different water-bearing states. Combined with NMR and SEM, the characteristics of microstructure of sandstone under different moisture conditions were studied. The results show that, with the increase of water content, the macromechanical parameters of sandstone gradually decrease, and the fine and microstructure characteristics are characterized by the gradual increase in the number of pores and the gradual increase in pore size. Based on the PFC2D software, considering the weakening effect of water on the partial cementation from a mesoscopic point of view, it is proposed to use soft and hard contacts to simulate the changes in the degree of cementation between particles under different water-bearing conditions and to study the impact of sandstone micromechanical parameters with changes in water content. Related research results can provide theoretical guidance for the stability evaluation of wading rock mass engineering.
\end{abstract}

\section{Introduction}

People's understanding of water-rock interaction in engineering comes from the obvious difference between the physical and mechanical properties of rocks in the saturated state and those in the dry state. It is found that the physical and mechanical properties of rocks in the saturated state have a significant decreasing trend $[1,2]$. Water is one of the unavoidable occurrence conditions of rock mass engineering [3]. With the rapid development of rock mass engineering such as slopes $[4,5]$, tunnels $[6,7]$, and underground caverns [8-11], water-rock interaction is highly valued. Rocks often contain microscopic defects such as pores and fissures, which become channels for water to enter the rock, thereby deteriorating its mechanical properties. The problem of rock mass engineering disasters caused by water is very common, so studying the mechanical properties of rocks under water- rock interaction is of great significance to rock mass engineering.

With the deepening of research on water-rock interaction, more and more scholars have carried out research on water-rock interaction from the microscopic level. In terms of the research on the change of rock mineral composition under water-rock interaction, Cui et al. [12-15] used X-ray diffraction experiments to study the change law and quantitative analysis of rock mineral content under waterrock interaction. As the water-rock interaction time increases, the clay mineral content generally shows a trend of increasing first and then decreasing. Song et al. [16-18] used the fluorescence spectroscopy test to study the change of the mineral composition of limestone under the action of water and rock and concluded that the content of $\mathrm{CaCO}_{3}$ and $\mathrm{SiO}_{2}$ changes exponentially as the osmotic pressure increases. In the study of the fine microstructure characteristics of rocks 
under water-rock interaction, Qiao et al. [19-21] used CT scanning technology to scan the rock samples damaged by water-rock interaction and found that the water-rock interaction leads to an increase in the mesopores of the rock, and the CT number shows an increasing trend. Zhong et al. [22-24] used nuclear magnetic resonance technology to test the porosity of rocks under different water-rock interaction conditions, found that the increase in water-rock interaction would lead to an increase in porosity, and established a quantitative relationship between porosity and rock mesoscopic damage. Wang et al. [25, 26] studied the influence of water-rock interaction on the microstructure characteristics of rocks based on scanning electron microscopy experiments and found that the damage degree of water and rock continues to increase, and its microscopic pores and cracks continue to increase, and the larger the value of the fractal dimension based on the scanning electron microscope image. The above research shows that the changes in the microscopic structure of rocks after encountering water are the main reason for the deterioration of macromechanical properties.

In recent years, the numerical simulation of particle flow based on the discrete element method has become an important way to study rock mechanics from a mesolevel perspective. Liu et al. $[27,28]$ studied the influence of waterrock interaction on the contact network, force chain distribution, and crack distribution of sandstone particles based on the particle flow software PFC2D. Jiang et al. [29, 30] analyzed the change law of the mechanical properties and failure modes of rocks under different water content conditions based on the discrete element particle flow method. Based on the particle discrete element method, Hu et al. [31] proposed a parallel bonding water-weakening model and analyzed the heterogeneity of cement, energy dissipation, inclination, failure mode of microcracks, and so on and revealed the mesomechanism of the weakening effect of water on rocks. The above research fully proves the feasibility and applicability of using particle flow software for waterrock interaction analysis.

Based on the abovementioned literature analysis, many scholars have conducted research on the degradation mechanism of rocks under water-rock interaction from the macroscopic and microscopic perspectives, and the research results have provided good guidance for engineering practice. However, in the study of the mechanical properties of sandstone under different water content conditions, based on the results of qualitative and quantitative analysis of rock microlevels, there are few studies on the mechanism of influence of different water content conditions on rock macromicromechanical properties from the perspective of mesoanalysis of the weakening of the cementation between the water-induced mesoparticles. Therefore, this paper selects the more common sandstone in rock mass engineering as the research object. Through uniaxial and triaxial compression tests, the macromechanical properties of sandstone under different water-bearing conditions are studied. Using nuclear magnetic resonance, scanning electron microscope, energy spectrum analysis, and other mesotesting methods, qualitative and quantitative analyses of sandstone mineral composition and microstructure characteristics and mesopore distribution characteristics were performed. Based on the discrete element software PFC2D, a numerical model considering different water content conditions is established for mesoanalysis. Integrating the macromechanical properties test results and the micro-microtest results reveals the macrofine-micromechanism of rock degradation by water. The research results can provide theoretical guidance for wading rock mass engineering.

\section{Test Project}

The rock sample used in this test is a slope sandstone from the Three Gorges Reservoir area. The sample used in the test is a standard cylindrical sample with diameter $\times$ height $=50 \mathrm{~mm} \times 100 \mathrm{~mm}$, as shown in Figure 1 .

Before the test, the quality, height, and diameter of the sample were measured, and the longitudinal wave velocity of the rock sample was measured using RSM-SY5(T) nonmetallic acoustic tester. Samples with small size deviations, smooth and flat surfaces, similar densities, and similar wave speeds were selected for use in the test. The selected samples were divided into three groups (A, B, and C), 15 samples in each group, 3 samples in each group are spares, $A$ is the dry group, B is the natural group, and $\mathrm{C}$ is the saturated group. The samples of group A were dried in an oven at $105^{\circ} \mathrm{C}$ for 12 hours, the samples of group B were kept in their natural state, and the samples of group $\mathrm{C}$ were dried in an oven at $105^{\circ} \mathrm{C}$ for 12 hours and then saturated by vacuum soaking in water for 24 hours. The masses after drying and the mass after being saturated with water were measured, and the moisture content of the sandstone in the dry, natural, and saturated states are $0,1.01 \%$, and $2.53 \%$, respectively.

2.1. Uniaxial/Triaxial Compression Test. Three samples from each group were taken for uniaxial compression test, nine samples from each were taken, and each three are divided into one type, and triaxial compression test was carried out with a confining pressure of 5,10 , and $15 \mathrm{MPa}$. The mechanical parameters of sandstone samples under different confining pressures were obtained, and the test equipment is shown in Figure 2. Force- (large-) displacement loading method was used for loading, and the loading rate of displacement is $0.005 \mathrm{~mm} / \mathrm{s}$.

2.2. Microstructure Test. Three samples of group $\mathrm{C}$ were selected randomly, and the low-field nuclear magnetic resonance analyzer was used as shown in Figure 2 for nuclear magnetic resonance scanning to obtain the T2 spectrum of rock samples and study the pore distribution in sandstone.

In order to study the microstructure of fracture surface of sandstone under different water-bearing conditions, Prisma E environmental scanning electron microscope was used to obtain SEM scanning images of sandstone fracture surface; EDS analysis system is used to analyze the elements in some areas of sandstone fracture surface, obtain energy spectrum, and study the mineral composition of sandstone. The scanning device of electron microscope is shown in Figure 3. 


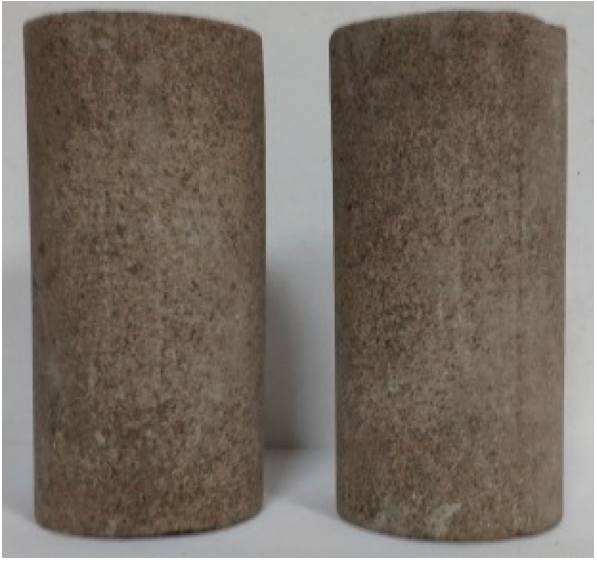

FIGURE 1: Sandstone sample.

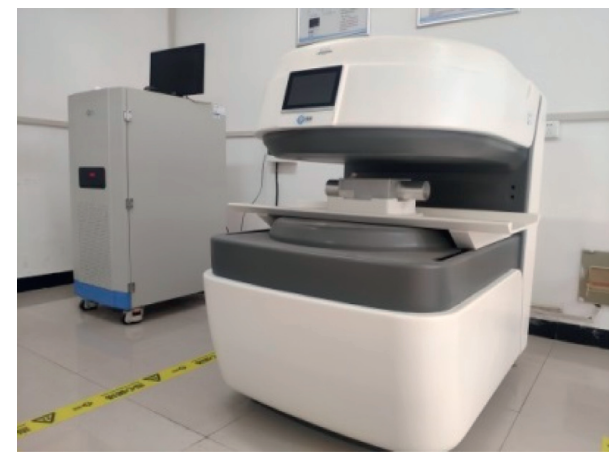

FIgURE 2: Low-field nuclear magnetic resonance analyzer.

\section{Study on the Change Law of Macromechanical Properties of Sandstone under Different Moisture Conditions}

3.1. Variation Law of Macroscopic Mechanical Parameters of Sandstone under Uniaxial Compression. Figure 4 shows the uniaxial compression stress-strain curves of sandstone specimens in three different states. The uniaxial compression curves of all samples have similar compaction stage, elasticity stage, plasticity stage, and failure stage. The difference is that the compaction stage of the dry sample curve is shorter and the plasticity stage is shorter, and the compaction stage of the saturated sample curve is longer, and there is an obvious plasticity stage. As the moisture content increases, the compaction stage gradually increases and the plasticity stage gradually becomes obvious.

According to Figure 4, the mechanical parameters of the rock samples in three states can be obtained. As shown in Table 1, the water content of sandstone increases by $1.01 \%$ from the dry state to the natural state, the uniaxial compressive strength decreases by $26.64 \mathrm{MPa}$, and the elastic modulus decreases by $2.66 \mathrm{GPa}$. The peak strain increased by $0.26 \%$; from the natural state to the saturated state, the water content increased by $1.52 \%$, the

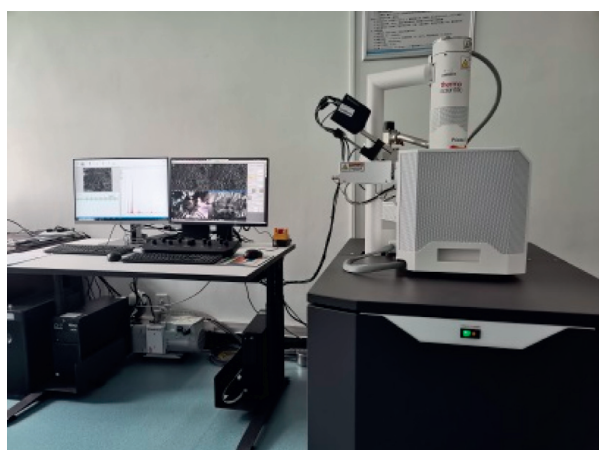

Figure 3: Prisma E environmental scanning electron microscope + EDS analysis system.

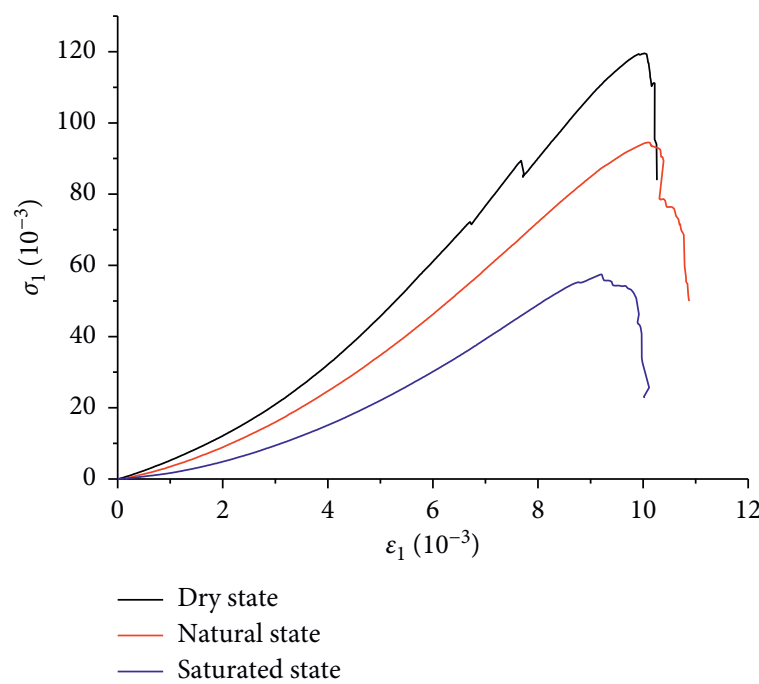

Figure 4: Stress-strain curves under uniaxial test.

uniaxial compressive strength decreased by $35.44 \mathrm{MPa}$, the elastic modulus decreased by $3.31 \mathrm{GPa}$, and the peak strain decreased by $1.08 \%$. The strength and elastic modulus of sandstone gradually decrease with the increase of water content, and water has a softening effect on sandstone.

3.2. Variation Law of Macroscopic Mechanical Parameters of Sandstone under Triaxial Compression. The peak strength of sandstone samples under different confining pressures under different water-bearing conditions is shown in Table 2. With the increase of confining pressure, the peak strength of sandstone samples gradually increases; under the same confining pressure, the peak strength of sandstone gradually decreases with the increase of water content.

According to the peak strength value measured by the triaxial compression test of sandstone, combined with the Mohr-Coulomb strength criterion, as shown in formula (1), the internal friction angle and cohesive force of sandstone in three water-bearing states are calculated, as shown in Table 3 . With the increase of water content, the internal friction angle and cohesive force of sandstone gradually decrease, 
TABLE 1: Mechanical parameters of sandstone in different states.

\begin{tabular}{lccc}
\hline Sample state & Elastic modulus $E(\mathrm{GPa})$ & Peak intensity б $(\mathrm{MPa})$ & Peak strain $\varepsilon(\%)$ \\
\hline Dry state & 15.63 & 119.54 & 10.03 \\
Natural state & 12.97 & 92.90 & 10.29 \\
Saturated state & 9.66 & 57.46 & 9.21 \\
\hline
\end{tabular}

Table 2: Peak strength of sandstone in triaxial compression test.

\begin{tabular}{lcccc}
\hline Confining pressure $(\mathrm{MPa})$ & 0 & 5 & 10 & 15 \\
\hline Dry state & 119.54 & 156.12 & 225.39 & 240.02 \\
Natural state & 92.90 & 124.02 & 164.68 & 201.70 \\
Saturated state & 57.46 & 82.40 & 120.07 & 149.76 \\
\hline
\end{tabular}

TABLE 3: Cohesion and internal friction angle of sandstone in different states.

\begin{tabular}{lcc}
\hline Sample state & $\begin{array}{r}\text { Internal friction } \\
\text { angle } \varphi\left(^{\circ}\right)\end{array}$ & $\begin{array}{c}\text { Cohesion } \\
c(\mathrm{MPa})\end{array}$ \\
\hline $\begin{array}{l}\text { Dry state } \\
\text { Natural state }\end{array}$ & 52.13 & 20.52 \\
$\begin{array}{l}\text { Saturated } \\
\text { state }\end{array}$ & 48.21 & 17.74 \\
\hline
\end{tabular}

and the water in the sandstone causes the bonding ability between mineral particles to decrease.

$$
\tau=\sigma \tan \varphi+c,
$$

where $\tau$ is the shear strength, $\sigma$ is the main stress, $\varphi$ is the internal friction angle, and $c$ is the cohesive force.

\section{Research on the Fine Microstructure Characteristics of Sandstone under Different Water Content Conditions}

4.1. Sandstone Mineral Composition Analysis. The energy spectrum of EDS analysis in some areas of sandstone section is shown in Figure 5. The sandstone contains quartz, feldspar, mica, chlorite, and other minerals. The mineral debris is mainly quartz, mica, and feldspar, chlorite is the main filling mineral, and the larger mineral particles are quartz and feldspar.

\subsection{Research on the Structural Characteristics of Sandstone Microfailed Sections under Different Water Content Conditions}

4.2.1. Analysis of Failure Section under Uniaxial Compression. Figure 6 shows the scanning electron microscope image of the uniaxial compression failure rock sample with a magnification of 100 times. Figures 6(a)-6(c) show the uniaxial failure cross section diagrams of the sandstone in the dry, natural, and saturated state, using the IPP software. The cross-sectional diameter of broken mineral particles and the particle size of intact mineral particles are measured. According to the analysis of sandstone mineral composition, it can be known that the observed broken minerals and intact minerals are quartz or feldspar. The following can be observed from Figure 6:
(1) Dry sandstone is destroyed by uniaxial compression, and there are a large number of broken fracture surfaces of mineral particles at the section. When dry sandstone is destroyed, the larger mineral particles are mainly broken.

(2) The natural state sandstone is destroyed by uniaxial compression. There are broken sections of mineral particles, complete mineral particles, and pores separated from mineral particles. Larger mineral particles are mainly broken. When the sandstone in the natural state is destroyed, the larger mineral particles are still broken and fractured, and the larger mineral particles are separated from each other due to the separation of the cementing material.

(3) During uniaxial compression failure in the saturated state, the proportion of intact mineral particles and the separation holes of mineral particles at the section increase, and there are also broken minerals, each accounting for $50 \%$. The saturated sandstone is destroyed, the cementation material separates, and the mineral particles separate from each other, and the separation of larger mineral particles is equivalent to the fragmentation.

In the process of uniaxial compression test, due to the inhomogeneity of sandstone material, there are compressive stress, shear stress, and tensile stress inside the sandstone; under the action of three kinds of stress, the rock sample will eventually be destroyed. In the dry and natural state of the rock sample, the larger mineral particles are mainly broken. With the increase of water content, the separation of the cementing material causes the larger mineral particles to not break, and the direct separation phenomenon increases. The direct separation phenomenon of the larger mineral particles in the saturated state reaches the highest. In the process of rock sample compression, it is easier to separate the cementitious material in the saturated state, and it is more difficult to separate the cementitious material in the dry state. As the moisture content increases, the bonding ability of the cementitious material gradually decreases.

\subsubsection{Analysis of Fracture Shape and Characteristics.} Figure 7 shows the SEM scans of fractures of sandstone in different states, magnified by 1200 times. Figures 7(a)-7(c) show the SEM scans of uniaxial compression failure in dry, natural, and saturated states, respectively. The following can be observed from Figure 7:

(1) In the dry state, the cross section of the rock sample mineral particles is smooth and flat, and there are small areas of fold-type lines and longer continuous 


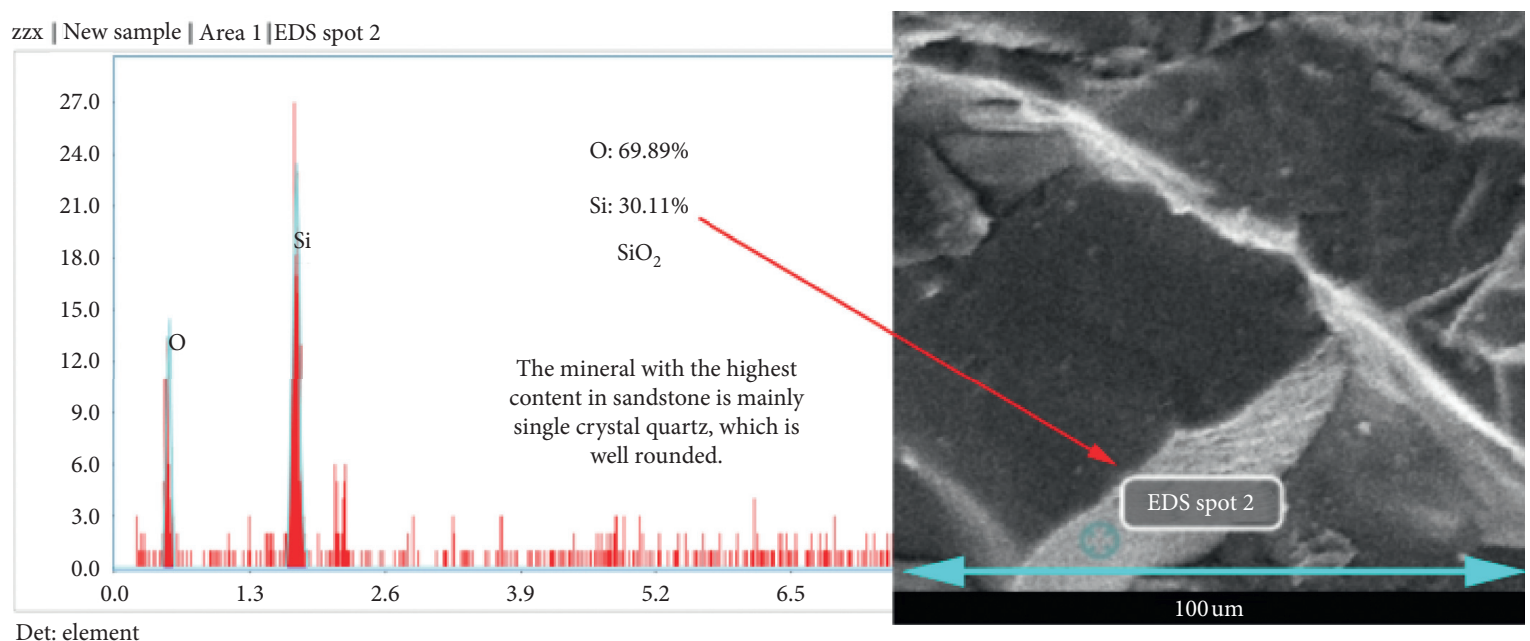

(a)

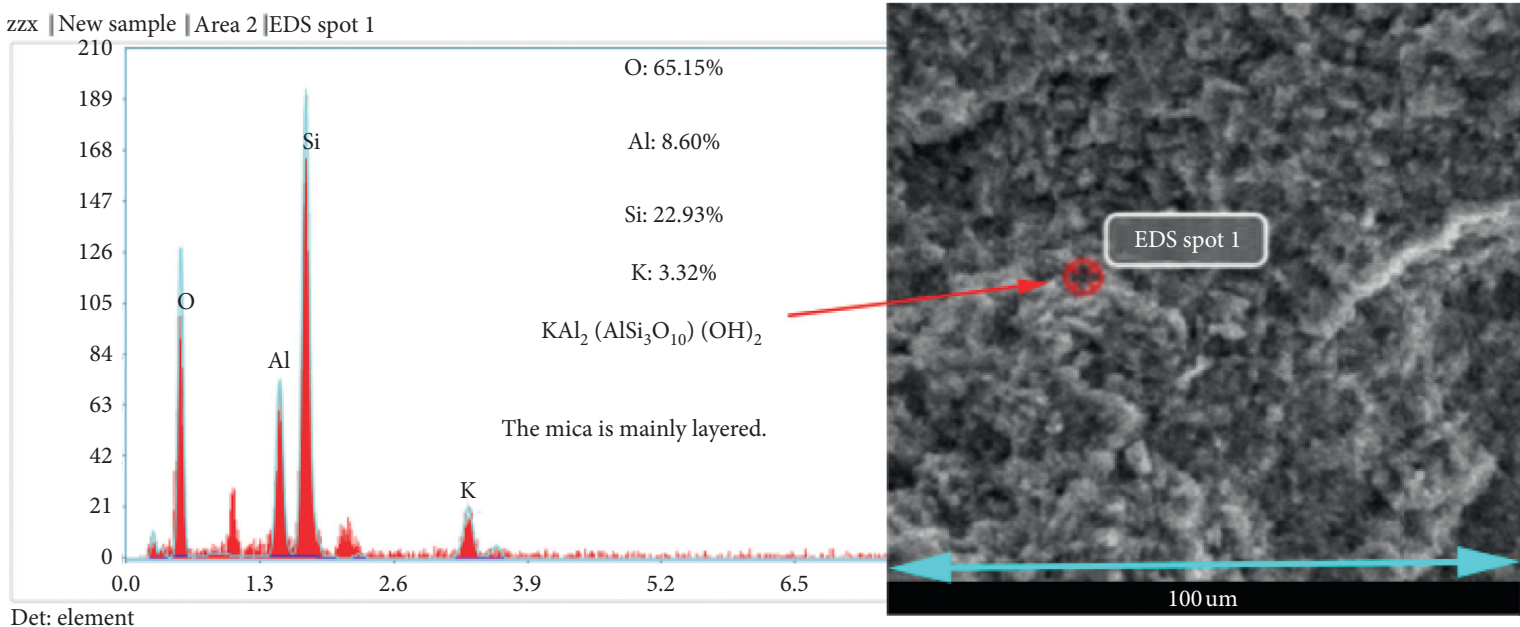

(b)

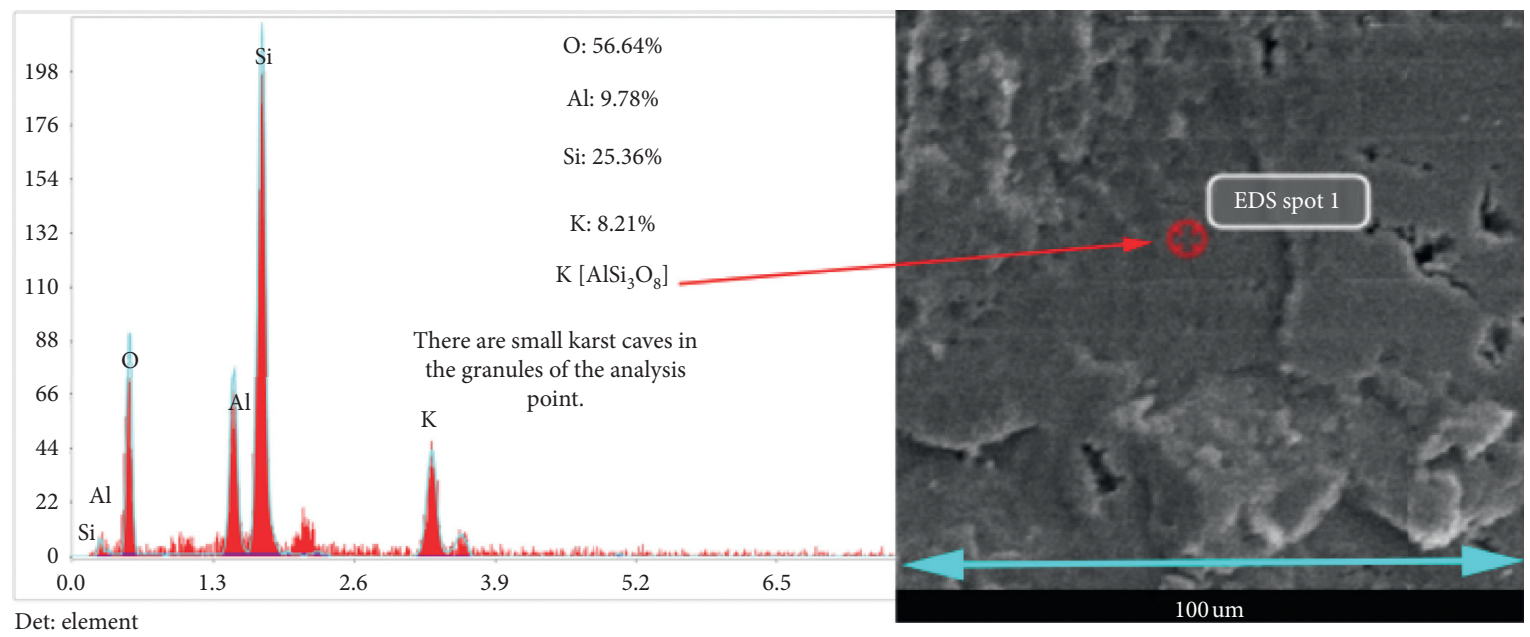

(c)

Figure 5: Continued. 


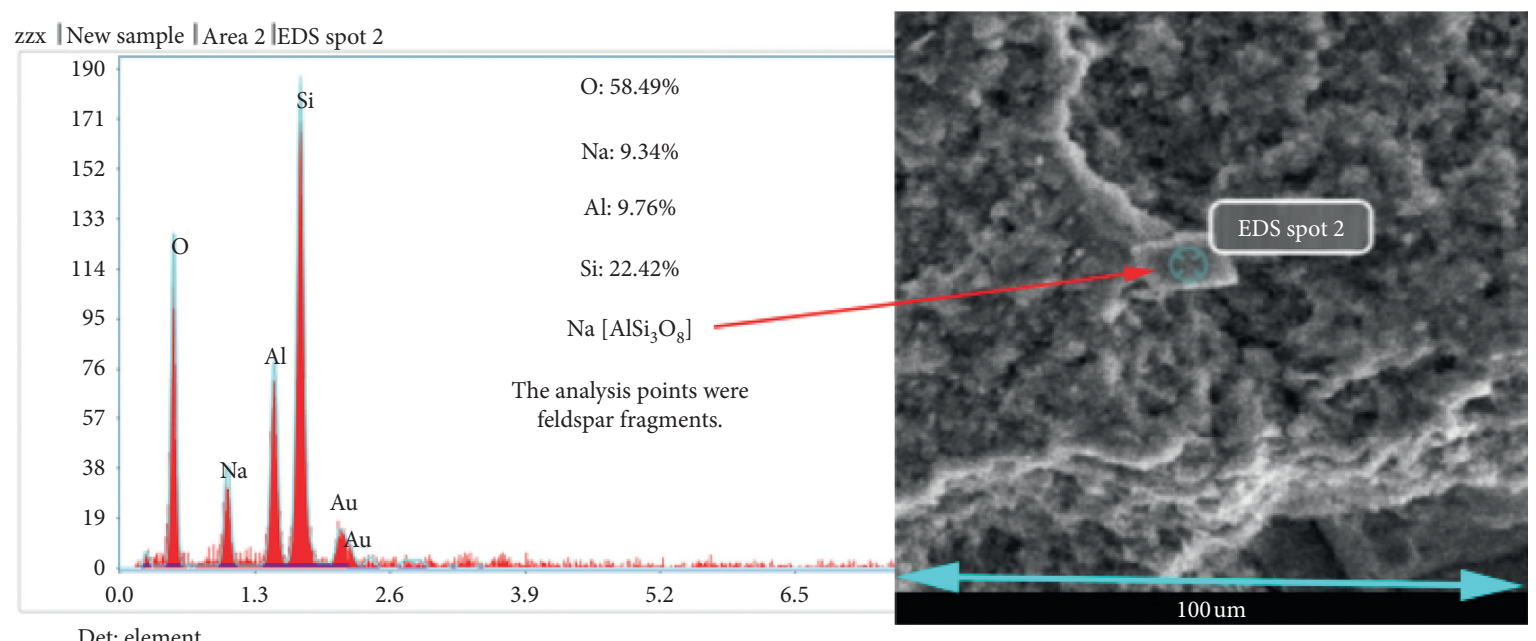

(d)
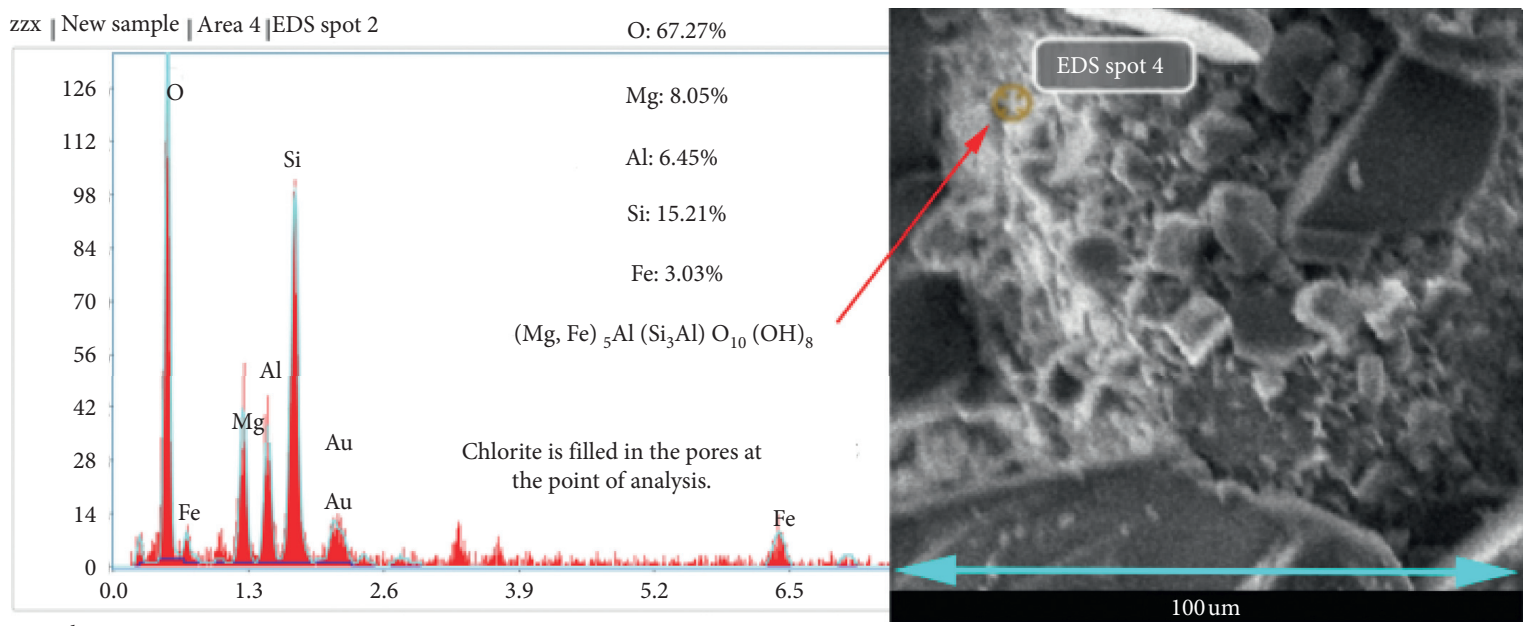

Det: element

(e)

Figure 5: The results of energy spectrum analysis: (a) quartz, (b) mica, (c) potash feldspar, (d) albite, and (e) chlorite.

lines, both of which are smooth; there are obvious penetrating cracks between the mineral particles, and there are small nonpenetrating mineral particles. Fissures mainly produce mineral particles.

(2) In the natural state, the section of the rock-like mineral particles is smooth and flat, the texture is smooth, and there are angular mineral fragments on the surface. There are continuous cracks between the mineral particles, and the fracture of the mineral particles is straight.

(3) In the saturated state, the section of the rock sample mineral particles is rough, the surface is attached with mineral fragments, and the large area has long stratified roads with tortuous shapes. The mineral particles have large cracks that are completely penetrating, the fractures are tortuous, and the particles are connected. There are penetrating fissures at places, fissures exist in and between mineral particles.
In a word, with the change of water content, the fracture surface of mineral particles is smooth in the dry state and becomes rough and tortuous in the saturated state. The cracks in the mineral particles change from small in the dry state to wide and continuous in the saturated state. It shows that the greater the water content in sandstone, the more obvious the softening of water-soluble mineral particles.

\subsection{Research on the Distribution of Micro-Pore Characteristics of Sandstone}

4.3.1. NMR T2 Spectrum Analysis. In the NMR T2 spectrum analysis, the size of the relaxed sample $\mathrm{T} 2$ is positively related to the pore size, and the area of the T2 spectrum curve is positively related to the number of pores. The larger the spectrum area, the more the number of pores. In Zhang et al.'s study [32], pores are divided into six categories: ultramicropores, with a pore diameter of less than $0.01 \mu \mathrm{m}$; micropores, with a pore diameter in the range of $0.01 \sim$ 


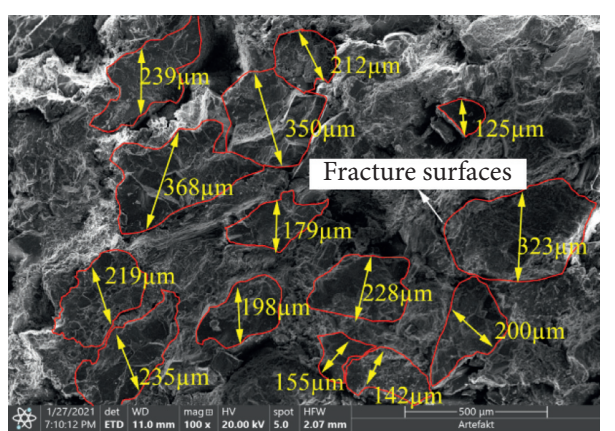

(a)

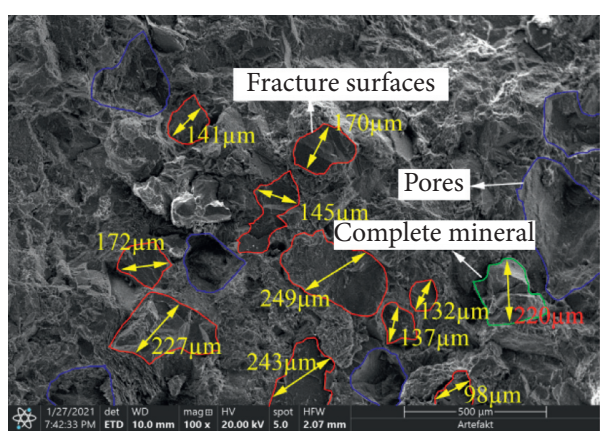

(b)

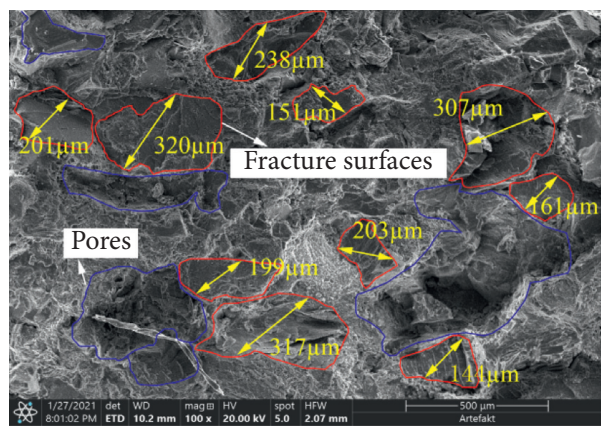

(c)

FIGURE 6: Failure section of rock samples in different states under uniaxial compression ( $\times 100)$ : (a) dry state, (b) natural state, and (c) saturated state.

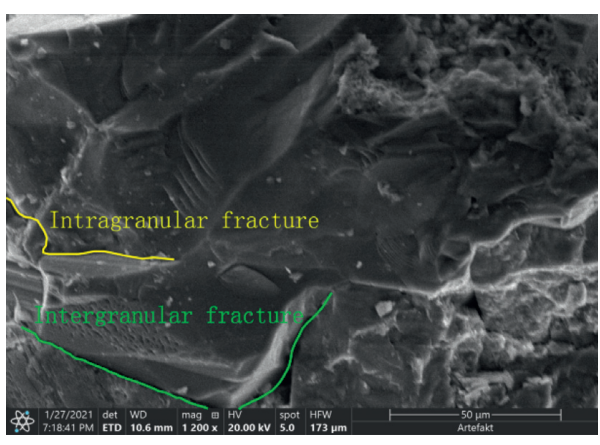

(a)

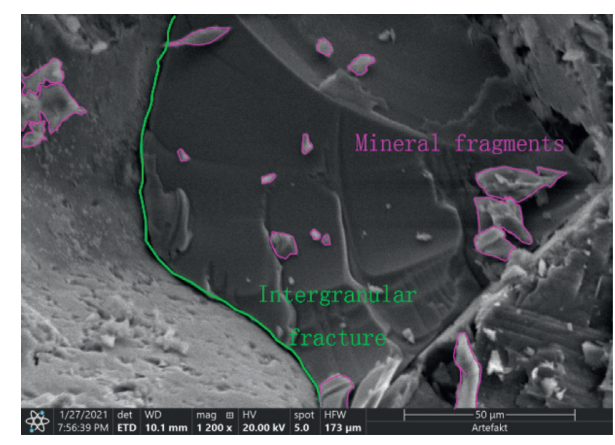

(b)

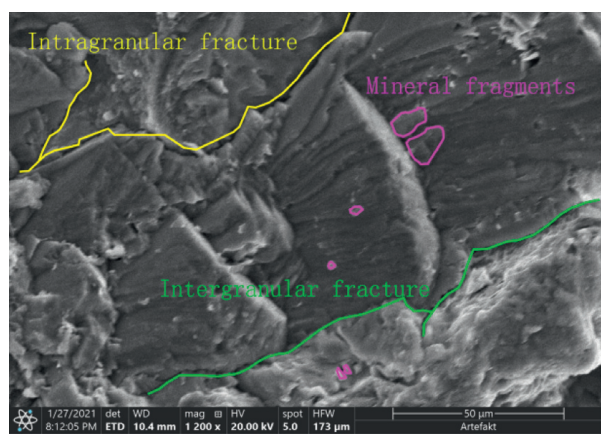

(c)

FiguRe 7: Cross section structure of sandstone in different water-bearing states ( $\times 1200)$ : (a) dry state, (b) natural state, and (c) saturated state. 
$0.1 \mu \mathrm{m}$; small pores, with a pore diameter in the range of $0.1 \sim 1 \mu \mathrm{m}$; mesopores, with a pore diameter of $1 \sim 10 \mu \mathrm{m}$; large pores, with a pore diameter of $10 \sim 100 \mu \mathrm{m}$; superlarge pores, with pore diameter greater than $100 \mu \mathrm{m}$. The T2 spectrum distribution of saturated rock samples is shown in Figure 8 . The following can be observed from Figure 8.

There is only one peak in the T2 spectrum distribution curve of the rock, which appears at $0.8 \mathrm{~ms}$, indicating that the pores inside the sandstone are mainly small pores and there are few large pores. The pore size in the sandstone is mainly distributed in the range of $0-0.01 \mu \mathrm{m}$. The pores in the sandstone are mainly ultramicropores, and the proportion of mesopores is low. There are no macropores and superlarge pores in the sandstone. The porosity of sandstone is $1.9451 \%$.

4.3.2. Analysis of Pore Structure Changes in Different States. Sandstone is framed by larger mineral particles such as quartz and feldspar and is filled with smaller clay mineral particles and clastic particles. The cementitious material connects the mineral particles. There are a large number of fine pores and cracks in the sandstone. The difference in the water content of the sandstone will cause the pore structure in the sandstone to be different. Select the SEM scanning images of the cementation sites of the sandstone fragments under uniaxial compression failure in three water-bearing states, and the magnification is 1200 times, as shown in Figure 9. Figures 9(a)-9(c) show dry, natural, and saturated states, respectively. Measure pores with a pore diameter greater than $0.5 \mu \mathrm{m}$. The following can be seen from Figure 9:

(1) In the dry state, the cementation material between the debris particles is uniformly filled, with a small amount of primary pores and inconspicuous cracks. The measured pore diameter is in the range of $0.82 \mu \mathrm{m}-3.20 \mu \mathrm{m}$, which belongs to the larger pores and the smaller mesopores.

(2) In the natural state, the clastic particles are filled with cement, and large pores appear locally, with a diameter of $1.87 \mu \mathrm{m}-5.82 \mu \mathrm{m}$, which are mesopores. In the natural state, the primary pores in the sandstone developed and opened under the action of water, and some of the larger small pores developed into mesopores. The original mesopores were expanded, and the pore diameter and number of mesopores increased.

(3) The clastic particles in the saturated state are loosely arranged, some mineral particles are separated, and many larger pores appear. The pore diameter is $1.75 \mu \mathrm{m}-6.2 \mu \mathrm{m}$, which belongs to mesopores. This is consistent with the pore diameter of sandstone measured by nuclear magnetic resonance not greater than $10 \mu \mathrm{m}$. After being fully saturated, the number of mesopores in the sandstone further increases, and the pore size distribution of mesopores does not change much.

4.3.3. Pore Fractal Characteristics. Voss et al. [33] analyzed the relationship between the perimeter and area of the pores

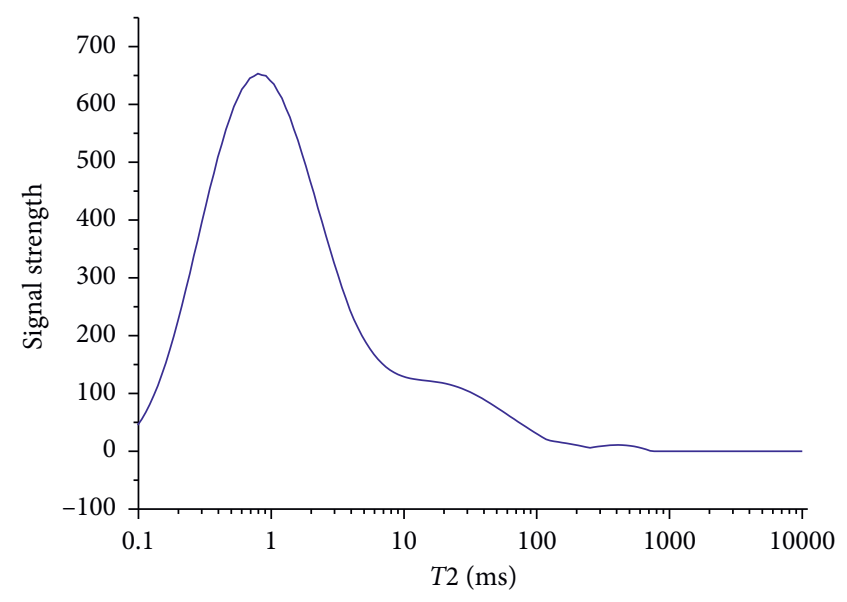

FIgURE 8: T2 spectrum distribution of full water samples.

in the rock and calculated the fractal dimension of the pores. The pore area, pore perimeter, and fractal dimension in sandstone conform to the following relationship:

$$
\lg C=\frac{D}{2} \times \lg A+d_{0},
$$

where $C$ is the pore circumference, $A$ is the pore area, $D$ is the fractal dimension of the pore shape in the image, and $d_{0}$ is a constant.

Select the SEM image $(650 \times)$ of the fracture section under uniaxial compression, use the IPP software to obtain the perimeter and area of each pore in the slate microscopic image, and draw the relationship between the pore area and the common logarithm of the pore perimeter, as shown in Figure 10. The fractal dimension is twice the slope.

It can be seen from Figure 10 that the fractal dimensions $D$ in dry, natural, and saturated states are $1.42,1.45$, and 1.48 , respectively. With the increase of the water content in the sandstone, the fractal dimension is increasing because of the increase in the water content of the sandstone. This leads to the dissolution of the cemented material in the sandstone, the expansion and deformation of the small pore-like circular pores in the dry state, the expansion of the pore size, the variety of shapes, and the increase of fractal dimensions.

\section{PFC2D Numerical Simulation and Analysis}

Silicate minerals such as feldspar, mica, and chlorite in sandstone are hydrolyzed in contact with water. Water has a softening effect on these minerals. Oxide minerals such as quartz in sandstone are less affected by water. Under the interaction of water and rock, the pore openings in the cemented material increase, the number increases, and the shape becomes diversified. The strength and bonding ability of the cemented material decrease, and the cemented material softens. Part of the cementitious material is little or not affected by the action of water. The pores in the cementitious material do not develop and remain intact. The water-saturated state of the cementitious material is completely in contact with water, and the pores are still dominated by ultramicropores. Short-term immersion in water will cause 


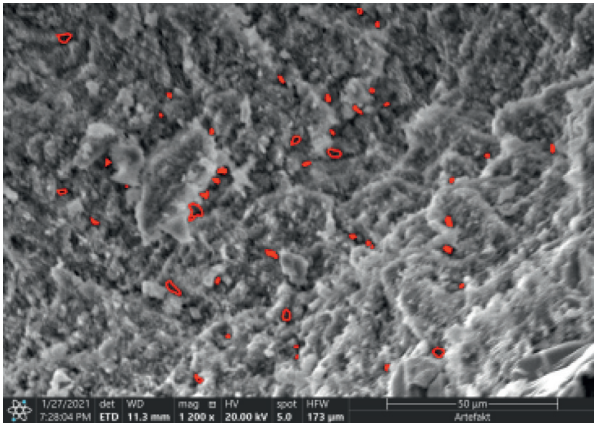

(a)

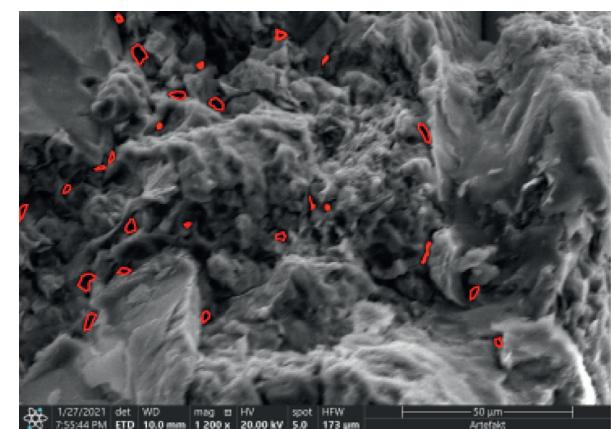

(b)

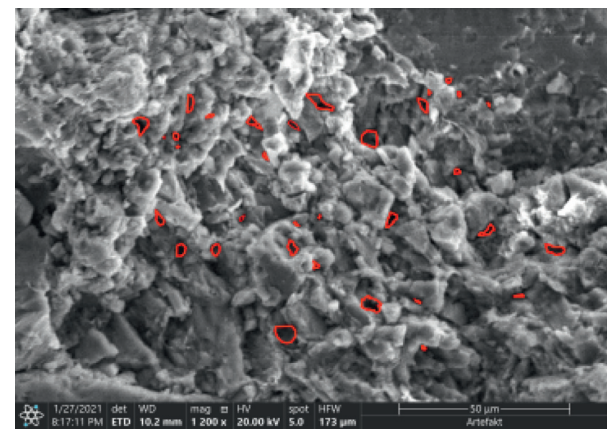

(c)

Figure 9: Pore structure of sandstone in different water-bearing states $(\times 1200)$ : (a) dry state, (b) natural state, and (c) saturated state.

the sedimentary cementation in the rock to soften, and the diagenetic cementation is not easy to soften. There are soft cementation that is easy to be softened by water and hard cementation that is not easy to be softened by water [34]. With the increase of water content, the softening degree of soft cement gradually increases, resulting in a decrease in the macroscopic mechanical parameters of sandstone. The particle flow discrete element method uses the contact mode between particles to simulate the macromechanical properties and deformation characteristics of materials with different properties. The discrete element software PFC2D is used to analyze the softening of the internal cementation material of sandstone, and the PBM bonding model is used for research. The two types of hard contact are used to simulate soft cementation that is easy to be softened by water and hard cementation that is not easy to be softened by water.

5.1. Model Establishment. Establish a PFC2D model with a size of $50 \mathrm{~mm} \times 100 \mathrm{~mm}$, set the particle generation radius to $0.3 \mathrm{~mm}-0.5 \mathrm{~mm}$, containing 8753 particles, the contact between the particles randomly generates $50 \%$ soft contact, $50 \%$ hard contact, and a total of 23,028 interparticle contacts, as shown in Figure 11 (In Figure 11(b), the green contacts represent soft contact and the blue contacts represent hard contact).

When calibrating the mesoparameters, first calibrate the model parameters in the dry state. The increase in water content will cause the soft cement to soften, that is, the soft contact parameters in the dry state, the natural state, and the saturated state will gradually change. The mesoparameters of sandstones with different water-bearing states were determined after trial and error and calculation. Table 4 shows the soft contact mesoparameters of sandstone in different waterbearing states. Among which the hard contact parameters do not change, the parallel bonding modulus of hard contact $E_{t h}=39.4 \mathrm{GPa}$, linear bonding modulus $E_{c h}=7.68 \mathrm{GPa}$, normal bonding strength $\sigma_{c n h}=86.4 \mathrm{MPa}$, and tangential bond strength $\sigma_{c s h}=72 \mathrm{MPa}$.

5.2. Model Loading Stress-Strain Curve Fitting. The stressstrain curve of uniaxial and triaxial compression has a compaction stage. The compaction stage is obvious during uniaxial compression. The elastic modulus of the compaction section increases with the increase of axial strain. After reaching the elastic stage, the elasticity modulus remains unchanged. In order to simulate the mechanical test results more realistically, a variable modulus model is used for uniaxial compression simulation. In the PFC model, the main parameters affecting the elastic modulus are the parallel bonding modulus $E_{t}$ and the linear bonding modulus $E_{c}$. The constitutive compaction is simulated by simultaneously changing the hard contact and soft contact parallel bonding modulus $E_{t}$. The change relationship is as follows:

$$
E_{t}=0.2 E_{t 0}+0.8 E_{t 0} \frac{\varepsilon}{\varepsilon_{0}}
$$

where $E_{t}$ is the parallel bonding modulus, $E_{t 0}$ is the parallel bonding modulus after compaction, $\varepsilon$ is the axial strain, and $\varepsilon_{0}$ is the axial strain at the end of compaction, which is determined by the actual constitutive relationship. 

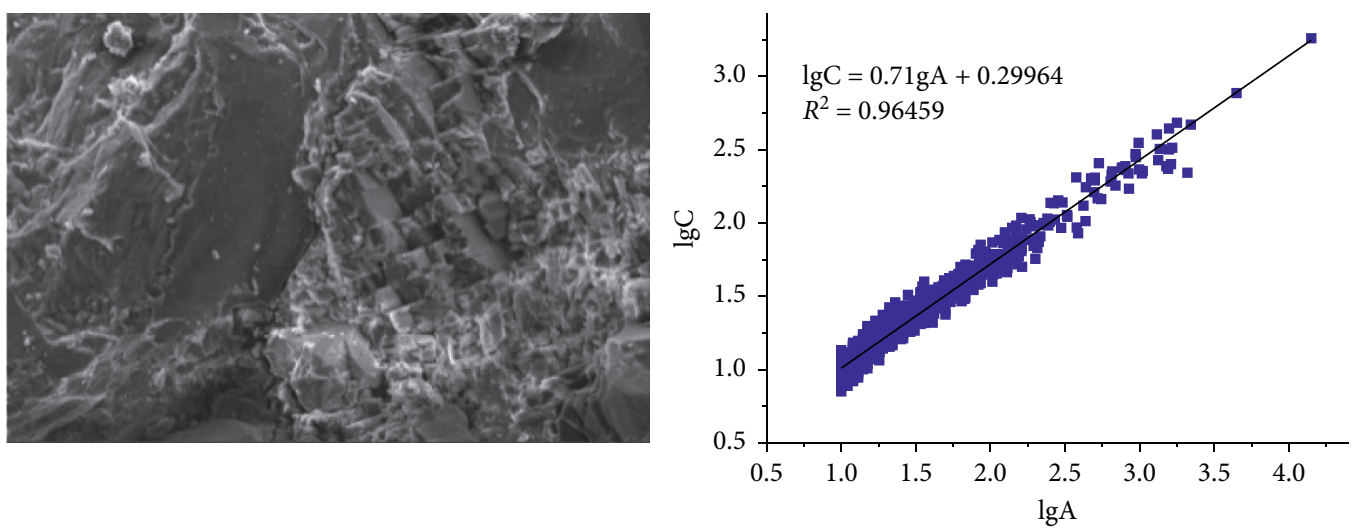

(a)
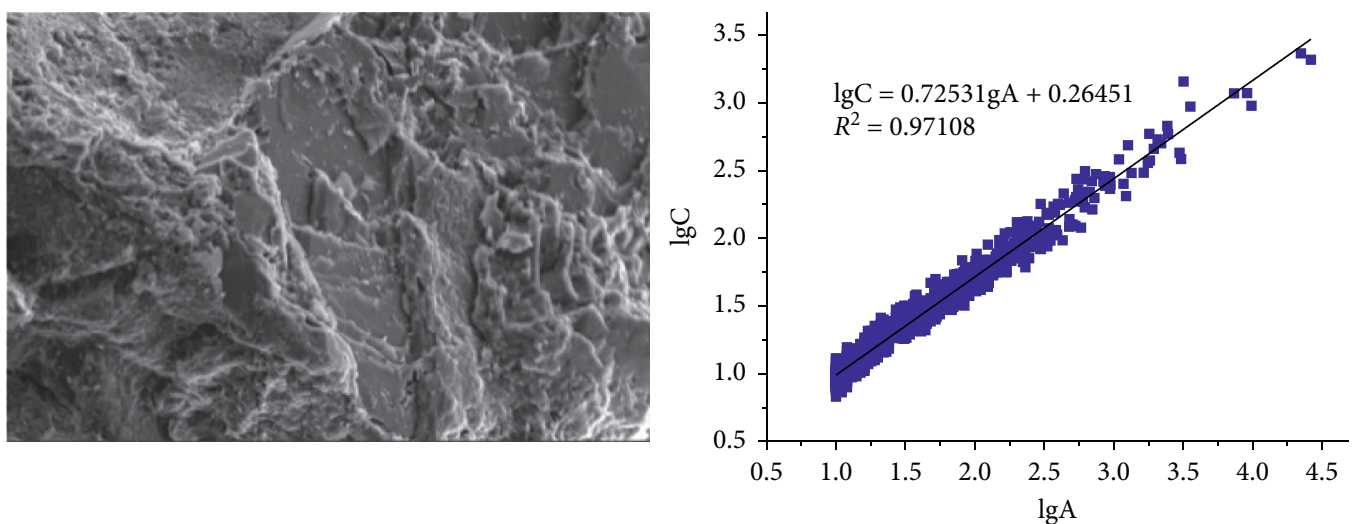

(b)
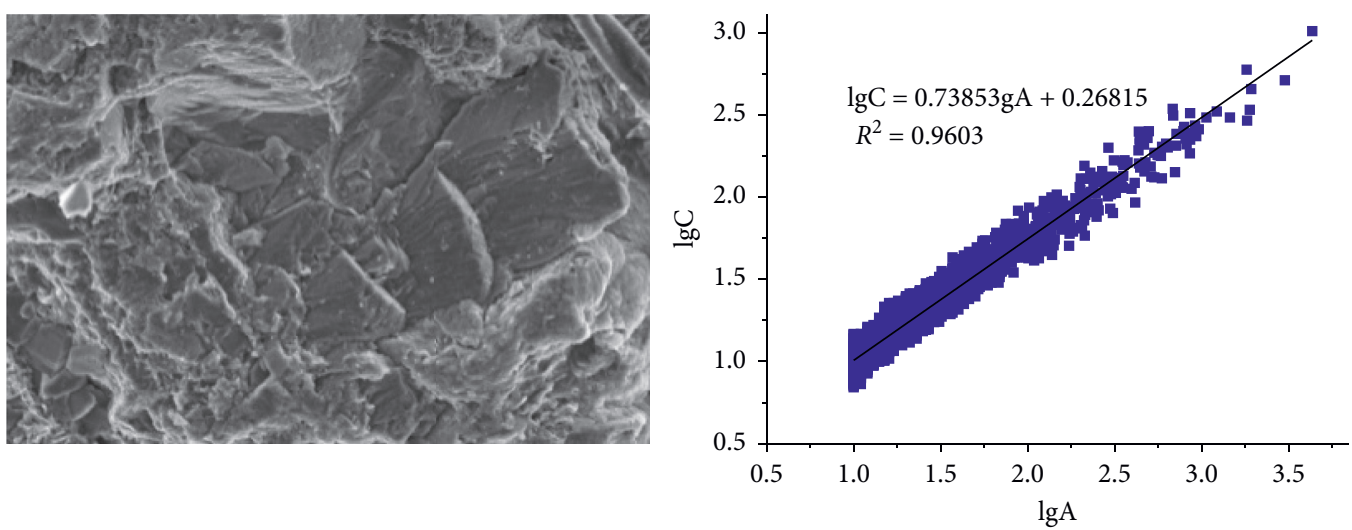

(c)

FIGURE 10: Fractal dimension relation between pore circumference and area in sandstone: (a) dry state, (b) natural state, and (c) saturated state.

The elastic modulus of the model is directly proportional to the parallel bond modulus parameters. From formula (3), the stress-strain relationship in the compaction stage can be deduced as follows:

$$
\sigma \propto 0.2 E_{t 0} \varepsilon+0.8 E_{t 0} \frac{\varepsilon^{2}}{\varepsilon_{0}} .
$$

From formula (4), it can be seen that the relationship between stress and strain becomes a quadratic function. The stress-strain curve of the variable modulus uniaxial compression simulation is shown in Figure 12. It can be found that the use of two contact variable modulus models can be very good. It fits the stress-strain curve of uniaxial compression in the dry, natural, and saturated state; in the compaction stage, the dry and natural state model can almost completely fit the actual constitutive relationship. But the actual axial stress in the saturated state is lower than that of the saturated state model, indicating that the actual saturated sandstone stress and strain in the compaction section have a higher-order relationship. The saturated sandstone bears the same axial stress in the early stage of 


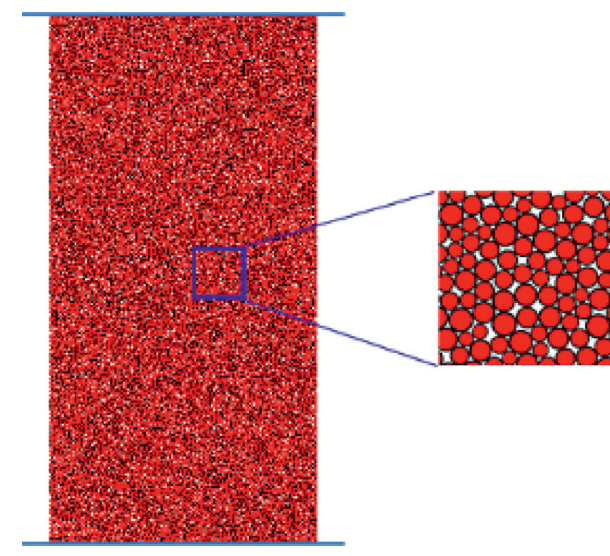

(a)

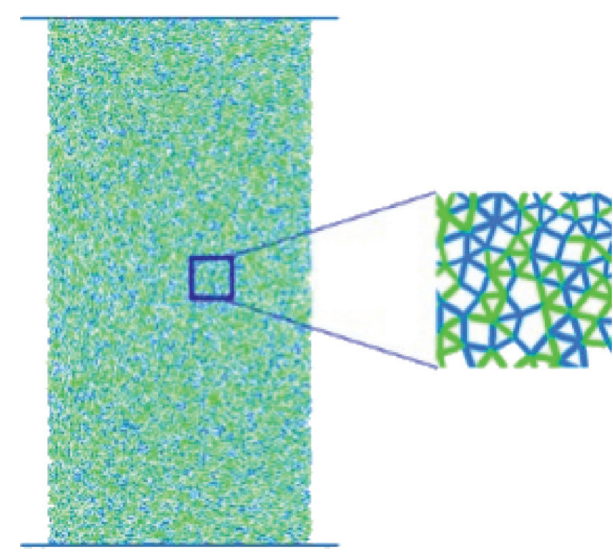

(b)

Figure 11: PFC model of sandstone specimen: (a) particle diagram and (b) contact diagram.

TABLE 4: Mesoparameters of sandstone in different water-bearing states.

\begin{tabular}{lcccc}
\hline Status & $E_{t s}(\mathrm{GPa})$ & $E_{c s}(\mathrm{GPa})$ & $\sigma_{c n s}(\mathrm{~Pa})$ & $\sigma_{c s s}(\mathrm{~Pa})$ \\
\hline Dry state & 23.45 & 4.36 & 80.08 & 72.80 \\
Natural state & 15.20 & 2.72 & 52.93 & 48.10 \\
Saturated state & 8.91 & 1.57 & 8.03 & 7.30 \\
\hline
\end{tabular}

$E_{t s}:$ soft contact parallel bond modulus; $E_{c s}$ : soft contact linear bond modulus; $\sigma_{c n s}$ : soft contact normal bond strength; $\sigma_{c s s}$ : soft contact tangential bond strength.

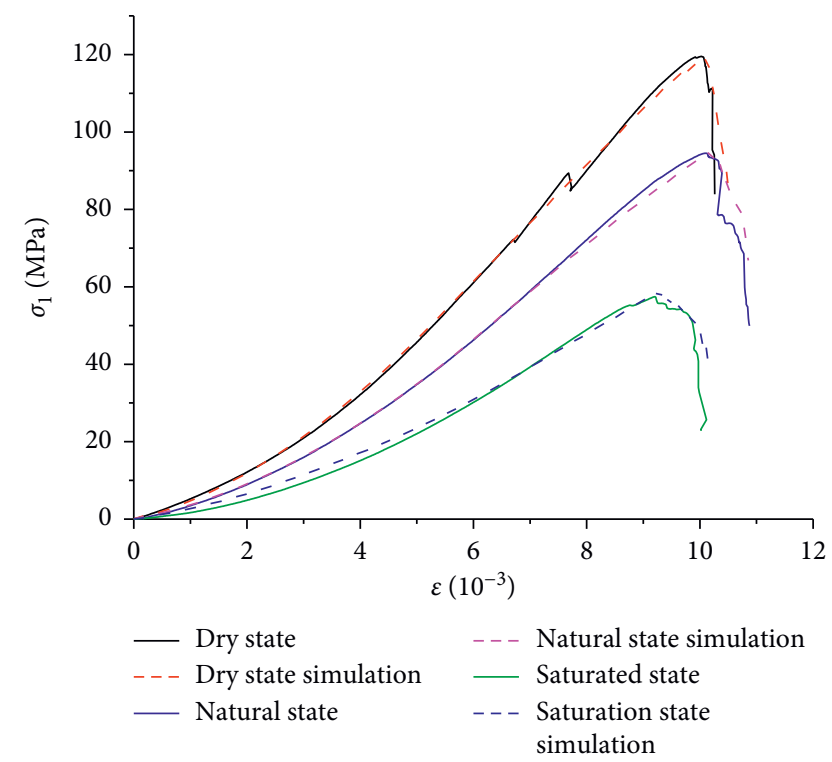

FIGURE 12: Comparison of variable-modulus uniaxial compression models.

compaction, and the axial strain changes. Larger, that is, the saturated sandstone is more "soft".

Comparing the result of indoor uniaxial compression and numerical simulation, it can be found that the uniaxial compressive strength of the numerical simulation samples under dry, natural, and saturated conditions is $119.34 \mathrm{MPa}$, 95.34 $\mathrm{MPa}$, and $58.77 \mathrm{MPa}$, respectively, the relative errors are $-0.17 \%, 0.87 \%$, and $2.3 \%$, and the relative errors are within 3\%. Therefore, it is feasible to use the soft-hard double-contact PBM model to simulate the uniaxial test of sedimentary and diagenetic mixed cemented sandstones affected by water deterioration.

Comparing the failure picture of the indoor uniaxial compression test sample with the failure mode of the PFC model, as shown in Figure 13, it can be found that the failure mode of the PFC model is similar to the failure mode of the indoor rock sample, and the simulation situation is in line with the reality; when the sandstone sample is damaged, the sandstone is broken into multiple rock blocks with different stress levels.

\subsection{The Influence of Different Water Content Conditions on the Microstructure of Sandstone}

5.3.1. Influence on the Distribution of Force Chains Between Particles. Figure 14 shows the distribution of force chains between sample particles in different states of specimen under uniaxial compression and peak stress conditions (the black force chain represents compression, and the red force chain represents tension. The thickness of the force chain is proportional to the magnitude of the bearing and transmitted load). The following can be observed from Figure 14 .

For the three hydrated samples, the number and thickness of the pressure chain are much greater than the tension chain. In the peak stress state, the pressure chain is the main load-bearing and load-transmitting force chain, and the overall direction of the pressure chain is along the axial direction. With the increase of moisture content, the proportion of the pressure chain gradually increases, and the proportion of the tension chain gradually decreases; in the dry state, the pressure-strength contact force chain and the tension-strength contact force chain cover the entire sample. With the increase of the rate, the chain of strong contact force gradually decreases, and the distribution gradually disperses. The decreasing trend of the chain of strong contact force under tension is more obvious. This indicates that the higher the water content, the more easily the strength of the 


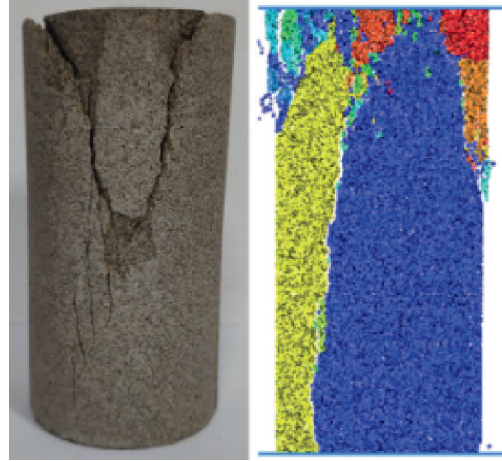

(a)

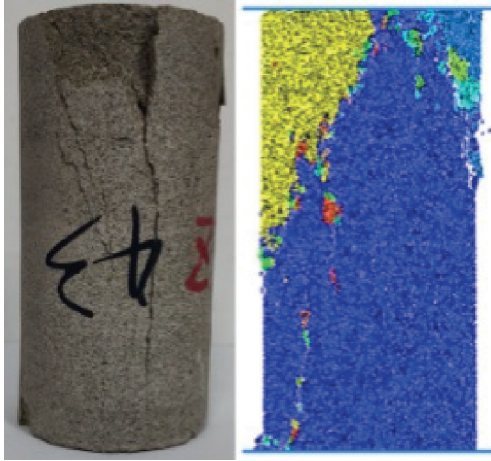

(b)
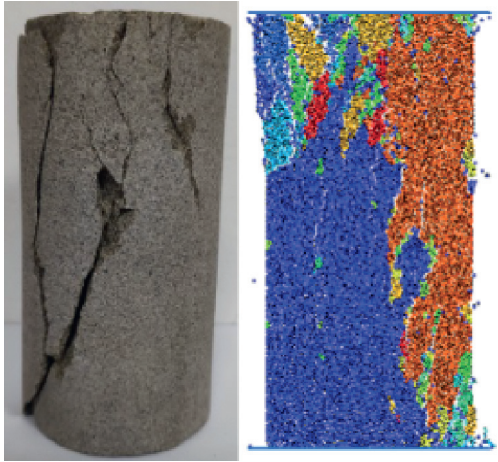

(c)

FIgURE 13: The amount of contact varies among different models: (a) dry state, (b) natural state, and (c) saturated state.

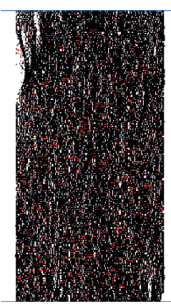

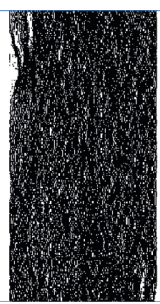

(a)
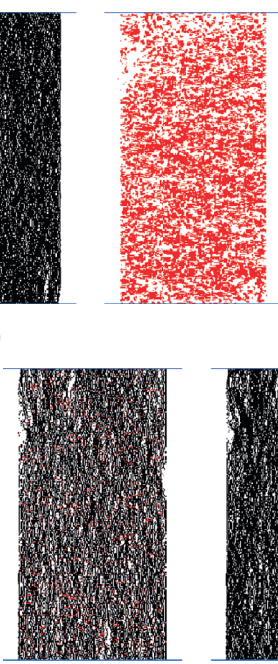
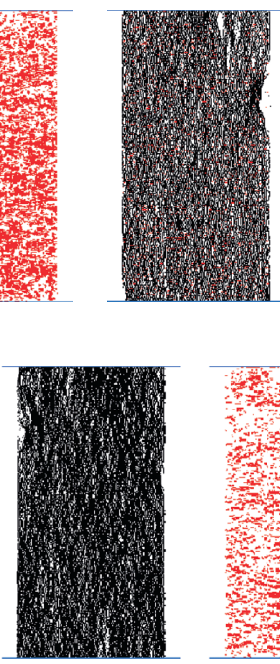

(c)

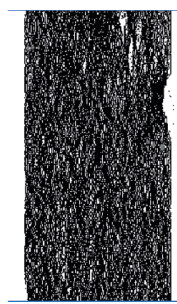

(b)

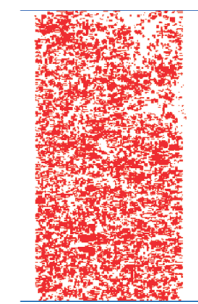

Figure 14: Distribution of force chains of specimens in different states: (a) dry state, (b) natural state, and (c) saturated state.

particles and the adhesion between the particles deteriorate. This is consistent with the higher the water content, the more obvious the softening effect of water on the cement and mineral particles.

5.3.2. Influence on the Number of Cracks and Changes in the Number of Contacts. When the postpeak stress is reduced to $20 \%$ of the peak value, the sample is completely destroyed. Figure 15 shows the change in the number of cracks and the final distribution of cracks during the uniaxial compression failure of samples in different water-containing states (blue cracks are tensile cracks, and green cracks are shear cracks). It can be seen that the number of uniaxial compression tensile cracks at the final failure is much greater than the number of shear cracks, and the microscopic view of uniaxial compression is dominated by tensile failure. The following can be found from Figure 15.

When the samples were completely destroyed, the numbers of tensile cracks in dry, natural, and saturated samples were 2893,3129 , and 5270 , respectively, and the numbers of shear cracks were 1257, 1501, and 3493, respectively. As the moisture content increases, the final total number of cracks, tensile cracks, and shear cracks continue to increase. The difference between tensile cracks and shear cracks keeps increasing. The distribution area of cracks in the dry state accounts for $60 \%$, and the cracks in the saturated state almost cover the entire sample, indicating that the higher the moisture content, the more obvious the tensile failure.

The occurrence and propagation of tension cracks and shear cracks in dry and natural models are basically the same. After reaching the peak value, it expands rapidly, and the extension of tensile cracks is much faster than that of shear cracks. After the tension cracks and shear cracks of the saturated model appear in the compaction stage, they rapidly expand first, and then the expansion speed slows down. After the axial stress reaches the peak value, the tension cracks expand sharply. The number of tension cracks increases significantly. When the moisture content is low, the crack propagation law in the sandstone is consistent. When the sandstone is fully saturated with water, the cracks in the sandstone expand irregularly. 

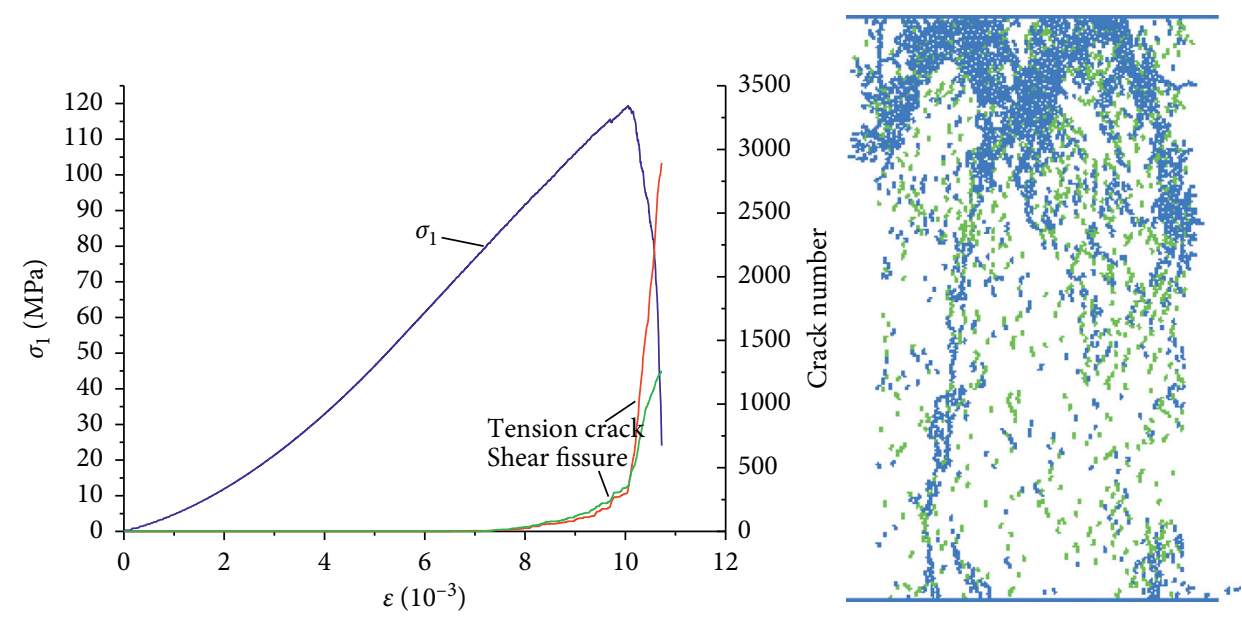

(a)
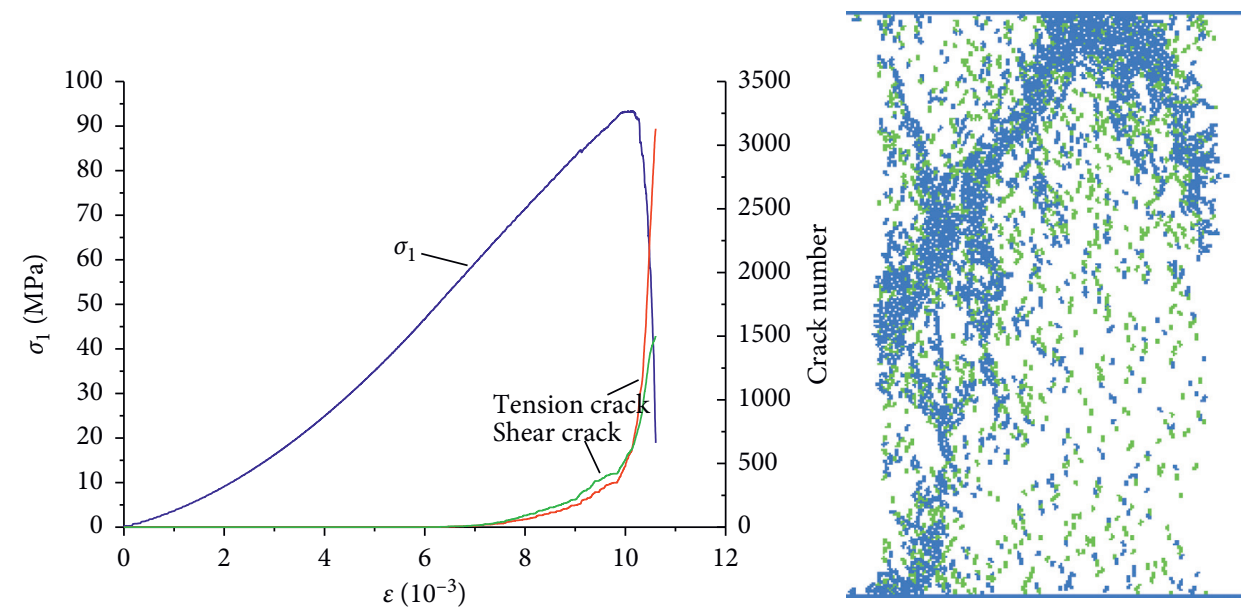

(b)
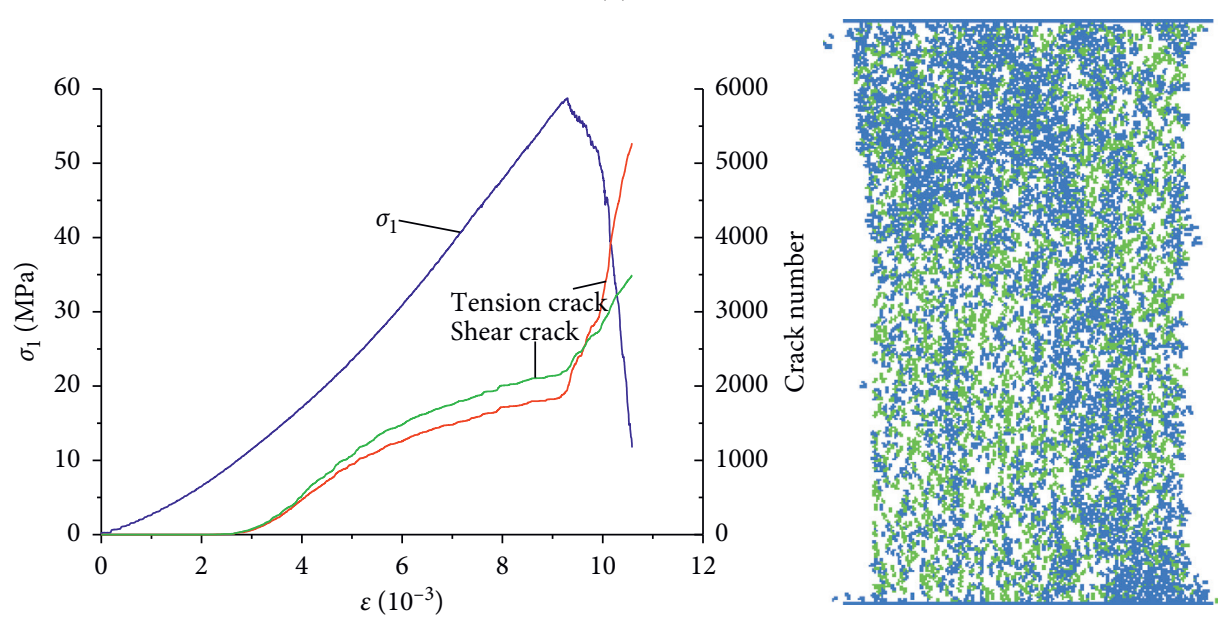

(c)

FIGURE 15: The number of cracks developed in different models: (a) dry model, (b) natural model, and (c) saturated model.

Figure 16 shows the changes in the number of soft and hard contacts in the uniaxial compression failure process of the models in different water states. It can be found that the soft contact of the three-state compression model fractures first, and the hard contact occurs after the failure. Comparing Figures 15 with 16, we can find the following.
The dry and natural models start to crack in the elastic stage, and the saturated model cracks in the compaction stage. The higher the moisture content, the easier the crack will appear, and the fracture in the compacted section is soft contact, and the soft cementation is affected by water. With the increase of water content, the bonding ability decreases. 


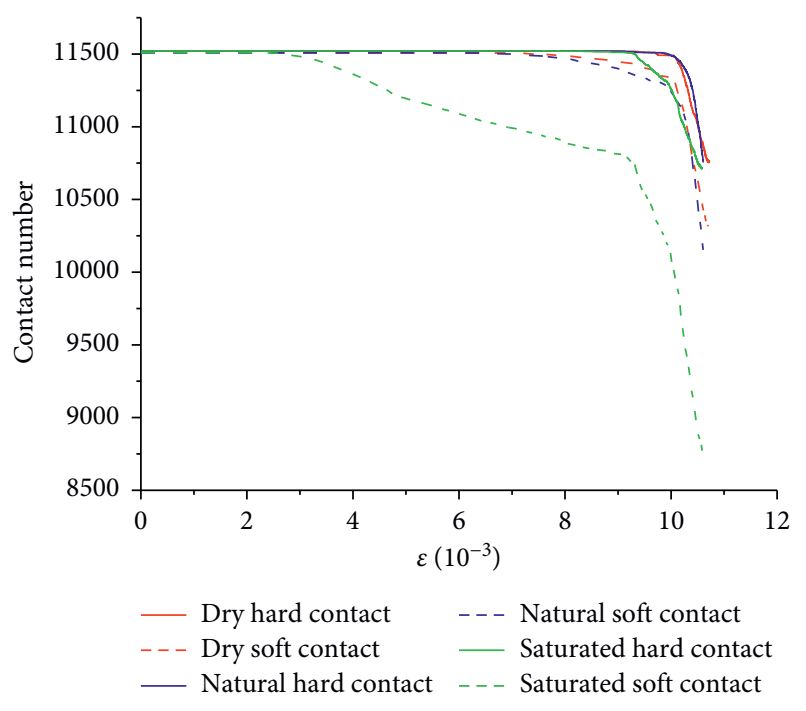

FIGURE 16: The amount of contact varies among different models.

When the water content of sandstone is low, the soft cementation is less affected by water. After the sandstone is saturated with water, the weak cementation is fully softened, and fracture occurs under less load.

Under the peak stress, there are 36 hard contact failures and 181 soft contact failures of the dry samples, 55 hard contact failures and 322 soft contact failures of the natural samples, and 19 hard contact failures and 758 soft contact failures of the saturated samples. The ratio of the number of hard contact damage to soft contact damage in dry, natural, and saturated samples is $0.20,0.17$, and 0.03 , respectively. With the increase of water content, the ratio of the number of hard-soft contact fractures decreases gradually under the peak stress state.

\section{Conclusion}

(1) Water has a weakening effect on sandstone. Water leads to a decrease in the cohesiveness between mineral particles in sandstone and changes in the macromechanical properties of sandstone. The water content of sandstone increases by $1.01 \%$ from the dry state to the natural state, the uniaxial compressive strength decreases by $26.64 \mathrm{MPa}$, and the elastic modulus decreases by $2.66 \mathrm{GPa}$.

(2) The water in sandstone has a softening effect on cementing materials and mineral particles, and the higher the water content, the more obvious the effect. With the increase of water content, the number of pores increases, the diameter becomes larger, and the shape of the pores becomes diversified. The distribution of pores in natural and saturated sandstone is almost the same, and water has a greater influence on the size of small pores.

(3) Based on the PFC2D discrete element simulation analysis, with the increase of water content, the deterioration of adhesion between particles intensifies. When the water content of sandstone is low, the soft cementation is less affected by water. After the sandstone is saturated with water, the weak cementation is fully softened, and the load-bearing capacity limit decreases.

\section{Data Availability}

The datasets generated and analysed during the current study are available from the first author upon reasonable request.

\section{Conflicts of Interest}

The authors declare that they have no conflicts of interest.

\section{Acknowledgments}

This work was supported by the Engineering Research Center of the Ministry of Education for the Ecological Environment of the Three Gorges Reservoir Area open foundation (no. KF2019-07), Natural Science Research Project of Yichang City (no. A21-3-005), National Natural Science Foundation of China (nos. 51809151, 51979218, U2034203, and U1965107), Natural Science Foundation of Shanxi Province (no. 2018JM5118), Open Fund of Key Laboratory of Ministry of Education (no. 2017KDZ01), and China Postdoctoral Fund (no. 2017M613167).

\section{References}

[1] C. G. Dyke and L. Dobereiner, "Evaluating the strength and deformability of sandstones," The Quarterly Journal of Engineering Geology and Hydrogeology, vol. 24, no. 1, pp. 123-134, 1991.

[2] A. B. Hawkins and B. J. Mcconnell, "Sensitivity of sandstone strength and deformability to changes in moisture content," The Quarterly Journal of Engineering Geology and Hydrogeology, vol. 25, no. 2, pp. 115-130, 1992.

[3] D. Gu, H. Liu, and X. Gao, D. Huang and W. Zhang, "Influence of cyclic wetting-drying on the shear strength of limestone with a soft interlayer," Rock Mechanics and Rock Engineering, pp. 1-10, 2021.

[4] C. Zhu, M.-c. He, M. Karakus, X.-h. Zhang, and Z. Guo, “The collision experiment between rolling stones of different shapes and protective cushion in open-pit mines," Journal of Mountain Science, vol. 18, no. 5, pp. 1391-1403, 2021.

[5] C. Zhu, M. He, M. Karakus, X. Zhang, and Z. Tao, "Numerical simulations of the failure process of anaclinal slope physical model and control mechanism of negative Poisson's ratio cable," Bulletin of Engineering Geology and the Environment, vol. 80, no. 4, pp. 3365-3380, 2021.

[6] C. Yang, Y. Chen, Z. Guo, W. Zhu, and R. Wang, "Surface settlement control in the excavation of a shallow intersection between a double-arched tunnel and a connection tunnel," International Journal of Geomechanics, vol. 21, no. 4, pp. 1-11, Article ID 04021035, 2021.

[7] C. Yang, Z. Hu, D. Huang, and F. Guo, "Failure mechanism of primary support for a shallow and asymmetrically loaded tunnel portal and treatment measures," Journal of Performance of Constructed Facilities, vol. 34, no. 1, pp. 1-13, Article ID 04019105, 2020. 
[8] Q. Wang, Z. Jiang, B. Jiang, H. Gao, Y. Huang, and P. Zhang, "Research on an automatic roadway formation method in deep mining areas by roof cutting with high-strength boltgrouting," International Journal of Rock Mechanics and Mining Sciences, vol. 128, Article ID 104264, 2020.

[9] Y. Wang, W. K. Feng, R. L. Hu, and C. H. Li, "Fracture evolution and energy characteristics during marble failure under triaxial fatigue cyclic and confining pressure unloading (FC-CPU) conditions," Rock Mechanics and Rock Engineering, vol. 54, no. 2, pp. 799-818, 2021.

[10] F. Wu, R. Gao, J. Liu, and C. Li, "New fractional variable-order creep model with short memory," Applied Mathematics and Computation, vol. 380, Article ID 125278, 2020.

[11] F. Wu, H. Zhang, Q. Zou, C. Li, J. Chen, and R. Gao, "Viscoelastic-plastic damage creep model for salt rock based on fractional derivative theory," Mechanics of Materials, vol. 150, Article ID 103600, 2020.

[12] Q. Cui, X. T. Feng, Q. Xue et al., "Mechanism study of porosity structure change of sandstone under chemical corrosion," Chinese Journal of Rock Mechanics and Engineering, vol. 27, no. 6, pp. 1209-1216, 2008.

[13] X.-T. Feng and W. Ding, "Experimental study of limestone micro-fracturing under a coupled stress, fluid flow and changing chemical environment," International Journal of Rock Mechanics and Mining Sciences, vol. 44, no. 3, pp. 437-448, 2007.

[14] X. Li and X.-S. Li, "Micro-macro quantification of the internal structure of granular materials," Journal of Engineering $\mathrm{Me}$ chanics, vol. 135, no. 7, pp. 641-656, 2009.

[15] L. L. Wang, M. Bornert, D. S. Yang et al., "Microstructural insight into the nonlinear swelling of argillaceous rocks," Engineering Geology, vol. 193, pp. 435-444, 2015.

[16] Z. P. Song, Y. Cheng, T. T. Yang et al., "Experimental study of the influence of osmotic pressure on pore structure evolution in limestone," Rock and Soil Mechanics, vol. 13, 2019.

[17] M. Farrokhrouz, M. R. Asef, and R. Kharrat, "Empirical estimation of uniaxial compressive strength of shale formations," Geophysics, vol. 79, no. 4, pp. 227-233, 2014.

[18] S. X. Ling, X. Y. Wu, C. W. Sun et al., "Experimental study of chemical damage and mechanical deterioration of black shale due to water-rock chemical action," Journal of Experimental Mechanics, vol. 31, no. 4, pp. 511-524, 2016.

[19] L. Qiao, J. Liu, and X. Feng, "Study on damage mechanism of sandstone under hydro-physico-chemical effects," Chinese Journal of Rock Mechanics and Engineering, vol. 26, no. 10, pp. 2117-2124, 2007.

[20] J. Fang, F. Dang, Y. Xiao et al., "Quantitative study ON the CT test process OF siltstone under triaxial compression," Chinese Journal of Rock Mechanics and Engineering, vol. 34, no. 10, pp. 1976-1984, 2015.

[21] H. Sun, X. L. Liu, and E. Z. Wang, "Prediction on uniaxial compression strength of rocks with $\mathrm{X}$-ray computed tomography," Chinese Journal of Rock Mechanics and Engineering, vol. 38, no. S2, pp. 3575-3582, 2019.

[22] Z. L. Zhong, W. K. Luo, X. R. Liu et al., "Experimental study on mechanical properties deterioration of limestone in acid environment based on nuclear magnetic resonance," Journal of China Coal Society, vol. 42, no. 7, pp. 1740-1747, 2017.

[23] Y. Song, L. Zhang, J. Ren et al., "Study on damage characteristics of weak cementation sandstone under drying-wetting cycles based on nuclear magnetic resonance technique," Chinese Journal of Rock Mechanics and Engineering, vol. 38, no. 4, pp. 825-831, 2019.
[24] N. Li, K. Wang, G. Zhang et al., "Prediction of gas production in carbonates based on CT analysis and nuclear magnetic resonance (NMR) logging," Petroleum Exploration and Development, vol. 42, no. 2, pp. 167-174, 2015.

[25] Z. J. Wang, X. R. Liu, Y. Fu et al., "Erosion analysis of argillaceous sandstone under dry-wet cycle in two $\mathrm{pH}$ conditions," Rock and Soil Mechanics, vol. 37, no. 11, pp. 3231-3239, 2016.

[26] Q.-X. Meng, W.-Y. Xu, H.-L. Wang, X.-Y. Zhuang, W.-C. Xie, and T. Rabczuk, "DigiSim - an open source software package for heterogeneous material modeling based on digital image processing," Advances in Engineering Software, vol. 148, Article ID 102836, 2020.

[27] X. R. Liu, D. L. Li, L. Zhang et al., "Influence of wetting-drying cycles on mechanical properties and microstructure of shaly sandstone," Chinese Journal of Geotechnical Engineering, vol. 38, no. 7, pp. 1291-1300, 2016.

[28] H. F. Deng, Y. Y. Zhi, L. L. Duan et al., "Research on the mechanical properties of sandstone and the damage evolution of microstructure under water-rock interaction," Rock and Soil Mechanics, vol. 40, no. 9, pp. 3447-3456, 2019.

[29] M. J. Jiang, N. Zhang, and H. Chen, "Discrete element simulation of aging effect of chemical weathering on rock," Rock and Soil Mechanics, vol. 35, no. 12, pp. 3577-3584, 2014.

[30] M. J. Jiang, P. Zhang, and Z. W. Liao, "DEM numerical simulation of rock under the influence of water softening and chemical weathering and chemical weathering in uniaxial compression test," Journal of China Institute of Water Resources and Hydropower Research, vol. 15, no. 2, pp. 89-95, 2017.

[31] J. X. Hu, K. Bian, J. Liu et al., "Discrete element simulation of shale softening based on parallel-bonded water-weakening model," Chinese Journal of Geotechnical Engineering, vol. 43, no. 4, pp. 725-733, 2021.

[32] Z. Z. Zhang, F. Gao, Y. N. Gao et al., "Fractal structure and model of pore size distribution of granite under high temperatures," Chinese Journal of Rock Mechanics and Engineering, vol. 35, no. 12, pp. 2426-2438, 2016.

[33] R. F. Voss, R. B. Laibowitz, and E. I. Allesandrin, "Fractal geometry of percolation in thin gold films," Scal-ing Phenomena in Disordered Systems, Plenum Press, New York, NY, USA, 1985.

[34] D. M. Gu, Failure Mechanism and Evolution of the Anaclinal High Carbonatite Rock Slopes with Soft Toes in the Three Gorges Region, Chongqing University, Chongqing, China, 2018. 